Open Access

\title{
Osteopontin mediates survival, proliferation and migration of neural stem cells through the chemokine receptor CXCR4
}

\author{
Monika Rabenstein ${ }^{1}$, Joerg Hucklenbroich ${ }^{1,2}$, Antje Willuweit ${ }^{3}$, Anne Ladwig ${ }^{1}$, Gereon Rudolf Fink ${ }^{1,2}$,
} Michael Schroeter ${ }^{1,2}$, Karl-Josef Langen $^{3}$ and Maria Adele Rueger ${ }^{1,2^{*}}$

\begin{abstract}
Introduction: Osteopontin (OPN) is a phosphoglycoprotein with important roles in tissue homeostasis, wound healing, immune regulation, and stress responses. It is expressed constitutively in the brain and upregulated during neuroinflammatory responses; for example, after focal cerebral ischemia. To date, its effects on neural stem cells (NSC) remain to be elucidated and are, accordingly, the subject of this study.

Method: Primary fetal rat NSC were cultured as homogenous monolayers and treated with different concentrations of OPN. Fundamental properties of NSC were assessed following OPN exposure, including proliferative activity, survival under oxidative stress, migration, and differentiation potential. To elucidate a putative action of OPN via the CXC chemokine receptor type 4 (CXCR4), the latter was blocked with AMD3100. To investigate effects of OPN on endogenous NSC in vivo, recombinant OPN was injected into the brain of healthy adult rats as well as rats subjected to focal cerebral ischemia. Effects of OPN on NSC proliferation and neurogenesis in the subventricular zone were studied immunohistochemically.

Results: OPN dose-dependently increased the number of NSC in vitro. As hypothesized, this effect was mediated through CXCR4. The increase in NSC number was due to both enhanced cell proliferation and increased survival, and was confirmed in vivo. Additionally, OPN dose-dependently stimulated the migration of NSC via CXCR4.

Moreover, in the presence of OPN, differentiation of NSC led to a significant increase in neurogenesis both in vitro as well as in vivo after cerebral ischemia.

Conclusion: Data show positive effects of OPN on survival, proliferation, migration, and neuronal differentiation of NSC. At least in part these effects were mediated via CXCR4. Results suggest that OPN is a promising substance for the targeted activation of NSC in future experimental therapies for neurological disorders such as stroke.
\end{abstract}

\section{Introduction}

Osteopontin (OPN) is an acidic phosphoglycoprotein containing the adhesive motif arginine-glycine-aspartate that interacts with various cell-surface integrins such as $\alpha v \beta 1, \alpha v \beta 3$, and $\alpha 5 \beta 1$ (reviewed in [1]). In response to injury and inflammation, OPN expression is induced in a number of cells including macrophages, activated $\mathrm{T}$ cells, osteoclasts, fibroblasts, epithelial cells, and vascular

\footnotetext{
* Correspondence: adele.rueger@uk-koeln.de

'Department of Neurology, University Hospital of Cologne, Cologne, Germany

${ }^{2}$ Cognitive Neuroscience, Institute of Neuroscience and Medicine (INM-3), Research Centre Juelich, Leo-Brandt-Straße, 52425 Juelich, Germany Full list of author information is available at the end of the article
}

smooth muscle cells [2-6]. Both a soluble isoform and an intracellular isoform exist (reviewed in [1]). OPN plays an important role in tissue homeostasis, wound healing, immune regulation, and stress response $[7,8]$. Intriguingly, under inflammatory conditions, it can stimulate both pro- and anti-inflammatory processes, depending on concomitant circumstances [7, 9-13]. In the brain, OPN is expressed constitutively and is upregulated with neuroinflammation (that is, in the subacute stage of cerebral ischemia) 3-6 days after stroke [14-17]. In cerebral ischemia, OPN mediates neuroprotection via two distinct mechanisms: a direct neuroprotective effect on (cortical) neurons $[18,19]$, and an indirect neuroprotective effect of OPN mediated via the transcriptional
C Biomed Central

(c) 2015 Rabenstein et al. This is an Open Access article distributed under the terms of the Creative Commons Attribution License (http://creativecommons.org/licenses/by/4.0), which permits unrestricted use, distribution, and reproduction in any medium, provided the original work is properly credited. The Creative Commons Public Domain Dedication waiver (http:// creativecommons.org/publicdomain/zero/1.0/) applies to the data made available in this article, unless otherwise stated. 
regulation of inducible nitric oxide synthase and consecutive reduction of secondary tissue damage [20].

Endogenous neural stem cells (NSC) residing in the subventricular zone (SVZ) and in the hippocampal dentate gyrus of the adult mammalian brain are mobilized following cerebral ischemia [21-23]. NSC mediate regeneration and functional recovery after stroke by way of neurogenesis and replacement of lost neurons, but also via pleiotropic functions including neuroprotection, reduction of neuroinflammation, revascularization, and induction of plasticity (reviewed in [24]). Their ability to migrate to a site of injury, to survive in the local environment, and potentially form new neurons, is crucial for their function but is often impaired after stroke $[25,26]$, contributing to the insufficient capacity of the brain for self-repair and functional recovery. Thus, supporting the proliferation, survival, and migration of endogenous NSC seems to be a promising therapeutic approach in stroke [22, 23, 27-31].

OPN is a potent chemoattractant, promoting the migration of cells of monocyte/macrophage lineage [32] as well as of osteoclast precursors [33], mesenchymal stem cells [34], and hematopoietic stem cells [35]. In the brain, NSC are typically recruited to sites of brain injury by the cytokine stromal cell-derived factor (SDF)- $1 \alpha$ that is expressed in the damaged tissue, acting on the CXC chemokine receptor type 4 (CXCR4). CXCR4 is expressed on various types of stem cells, including hematopoietic stem cells [36] and NSC [37]. Zhang et al. demonstrated that in cell lines from hepatocellular carcinoma, as an analogue of SDF-1, OPN can also bind to CXCR4 and promote cell migration [38].

To date, little is known about the effects of OPN on NSC. For neural progenitor cells grown in neurosphere cultures, OPN was suggested to increase proliferation [39] and migration [40, 41] by yet unknown mechanisms. We hypothesized that OPN promotes proliferation and migration of NSC through CXCR4 in vitro as well as in vivo as a potential means of mobilizing and attracting NSC to the brain after focal cerebral ischemia. Moreover, we examined the effects of OPN on the differentiation potential of NSC.

\section{Material and methods}

\section{Cell culture}

Primary NSC were cultured from fetal rat cortices at embryonic day 13.5 as serum-free monolayers [22]. Briefly, cells were plated on dishes coated with poly-Lornithine and fibronectin, and expanded in Dulbeccos's modified Eagle's/F12 medium (Life Technologies, Darmstadt, Germany) plus N2 supplement (Gibco, Karlsruhe, Germany), penicillin/streptomycin, L-glutamine, and sodium pyruvate. As a mitogen, fibroblast growth factor (FGF) 2 was included at $10 \mathrm{ng} / \mathrm{ml}$ throughout the experiments (Invitrogen, Karlsruhe, Germany). After first passaging, homogenous NSC cultures were re-plated at 10,000 cells per $\mathrm{cm}^{2}$. Only NSC from the second until the fifth passage were used for all experiments, in order to utilize unaltered primary cells.

\section{Immunocytochemistry}

All immunocytochemical experiments were performed in triplicate.

\section{Characterization of NSC}

Typical characteristics of NSC in culture were confirmed immunocytochemically to verify homogeneity of the cultures. Cells were fixed with $4 \%$ paraformaldehyde (PFA) and stained for: i) SRY (sex determining region Y) box 2 (SOX2) as a marker for undifferentiated (stem) cells (mouse monoclonal, dilution 1:1000, cat-\# MAB2018, R\&D Systems, Minneapolis, USA), and ii) their expression of the cytokine receptor CXCR4 (polyclonal rabbit, dilution 1:250, cat-\# 2042, Abcam, Bristol, UK). To detect a potential effect of OPN on the expression of CXCR4, NSC were treated in the presence or absence of $3.125 \mu \mathrm{g} / \mathrm{ml}$ OPN for $24 \mathrm{~h}$, then fixed in $4 \%$ PFA and stained for CXCR4. For visualization of SOX2 and CXCR4, fluorescein-labeled anti-rabbit immunoglobulin (Ig)G were used (dilution 1:200, Invitrogen); all cells were additionally counterstained with Hoechst 33342 (Life Technologies).

\section{Cell number assessment}

To assess the effects of OPN on NSC numbers, recombinant rat osteopontin (OPN; R\&D Systems) with concentrations ranging from $1.25-12.5 \mu \mathrm{g} / \mathrm{ml}$ was added to the cultures $1 \mathrm{~h}$ after re-plating. To assess the role of CXCR4 in mediating any effects of OPN on cell numbers, we blocked this receptor with the CXCR4antagonist AMD3100 (Tocris Bioscience, Bristol, UK) at a concentration of $10 \mu \mathrm{M}$ in some wells directly after replating, resulting in a pre-incubation time of NSC with AMD3100 of $1 \mathrm{~h}$ before adding OPN. After $72 \mathrm{~h}$, dead cells were stained with propidium iodide (Life Technologies). All cells, irrespective of viability, were counterstained with Hoechst 33342 (Life Technologies) and representative pictures were taken using an inverted fluorescence phase-contrast microscope (Keyence BZ-9000E; Keyence, Neu-Isenburg, Germany). Ten images were taken per well of a 24-well plate, and both Hoechst-stained and propidium iodide-stained NSC were counted manually. To calculate the ratio of living cells, the number of propidium iodide-negative cells was divided by the total (Hoechst-stained) number of NSC in each sample, and mean values were established among equally treated samples. Results were expressed as percent of the control \pm standard error of the mean (SEM). 


\section{Ki67 stainings}

To directly assess the effects of OPN on the proliferation of NSC, cells were treated with OPN at a concentration of $6.25 \mu \mathrm{g} / \mathrm{ml}$ for $72 \mathrm{~h}$ starting at re-plating. Cells were fixed with $4 \%$ PFA and were stained for the expression of the proliferation marker Ki67 (rabbit polyclonal, dilution of 1:500, cat-\# ab15580, Abcam). For visualization, fluorescein-labeled anti-mouse IgG was used; all cells were additionally counterstained with Hoechst 33342. Representative pictures were taken using an inverted fluorescence phase-contrast microscope (Keyence BZ-9000E), and Ki67-positive, proliferating NSC were counted manually. To calculate the ratio of proliferating cells, the number of Ki67-positive cells was divided by the total cell number in each sample, and mean values were established among equally treated samples. Results were expressed as percent of the control \pm SEM.

\section{Oxidative stress assay}

To assess the effects of OPN on NSC under oxidative stress, NSC were allowed to grow for $24 \mathrm{~h}$ after replating, and were then treated with $300 \mathrm{nM} 30 \% \mathrm{H}_{2} \mathrm{O}_{2}$ for $24 \mathrm{~h}$ (Merck, Darmstadt, Germany). OPN at 6.25 $\mu \mathrm{g} / \mathrm{ml}$ was added to NSC cultures either with plating (resulting in a pre-incubation time of $24 \mathrm{~h}$ before oxidative stress, pre-treatment), or at the same time as the addition of $\mathrm{H}_{2} \mathrm{O}_{2}$ (simultaneous treatment). After $24 \mathrm{~h}$ under oxidative stress with $\mathrm{H}_{2} \mathrm{O}_{2}$, NSC were co-stained with propidium iodide to label dead cells, and Hoechst 33342 to label all cells regardless of viability. Ten representative images were taken per well of the 24-well plate, and cells were counted manually. To calculate the ratio of dead cells, the number of propidium iodide-positive cells was divided by the total cell number in each sample, and mean values \pm SEM were established among equally treated samples.

\section{Low-density plating}

To further assess the effects of OPN in another cell stress model, NSC were plated at very low density (266 cells $/ \mathrm{cm}^{2}$ ) and grown in the presence or absence of OPN at $6.25 \mu \mathrm{g} / \mathrm{ml}$. After 8 days, NSC were co-stained with propidium iodide to label dead cells, and Hoechst 33342 to label all cells regardless of viability. Five representative images were taken per well of the 24-well plate, and cells were counted manually. To calculate the ratio of living cells, the number of propidium iodide-negative cells was divided by the total cell number in each sample, and mean values \pm SEM were established among equally treated samples.

\section{NSC migration}

NSC migration was analyzed via a trans-well migration assay using a modified Boyden chamber (CytoSelect ${ }^{\mathrm{TM}}$
24-Well Cell Migration Assay, $8 \mu \mathrm{M}$ pore size; Cell Biolabs, Inc., San Diego, USA) according to the manufacturer's protocol. Briefly, NSC were seeded in the inserted upper chamber. To assess the role of CXCR4 in mediating effects of OPN on migration, we blocked the receptor with AMD3100 at a concentration of $10 \mu \mathrm{M}$ in half of the wells directly after plating for $1 \mathrm{~h}$ as pre-incubation before adding OPN. After $1 \mathrm{~h}$, either $10 \mu \mathrm{g} / \mathrm{ml} \mathrm{OPN}, 10 \%$ fetal calf serum (FCS) as a positive control, or phosphate-buffered saline as a negative control, were added to the lower chambers of the modified Boyden chamber. After $48 \mathrm{~h}$, the non-migrating cells on the upper side of the inserts were removed with a cotton tip. The migrating cells on the lower side of the inserts were stained with Cell Stain Solution for 10 minutes (Cell Biolabs, Inc.). Subsequently, they were washed with phosphate-buffered saline and allowed to air dry, before they were incubated with the Extraction Solution (Cell Biolabs, Inc.). The optical density of each sample was measured at $560 \mathrm{~nm}$ in a plate reader (FLUOstar Omega; BMG LABTECH, Ortenberg, Germany). Mean values \pm SEM were established among equally treated samples, and results were expressed as percent of the control.

\section{NSC differentiation}

The differentiation potential of OPN-treated cells was investigated after withdrawal of the mitogen FGF2 during the expansion phase. After 7 days, the culture medium was replaced by Neurabasal Medium with GlutaMAX, penicillin/streptomycin, L-glutamine, sodium selenite, B27, NT3, and BDNF. After 7, 10, or 14 days of mitogen withdrawal in the absence (control) or presence of 6.25 $\mu \mathrm{g} / \mathrm{ml}$ OPN, NSC were fixed, then immunocytochemically stained for markers for neuron specific beta-III tubulin (anti-TuJ1; mouse monoclonal, dilution 1:100, R\&D Systems), mature neurons (anti-MAP2; mouse monoclonal, dilution 1:1000, Sigma-Aldrich, Munich, Germany), astrocytes (anti-GFAP; rabbit polyclonal, dilution 1:2500, Abcam), oligodendrocytes (anti-CNPase; mouse monoclonal, clone 11-5B, dilution 1:500, Millipore, Billerica, USA), and undifferentiated stem cells (SOX2; mouse monoclonal, dilution 1:1000, R\&D Systems). Besides staining for those single antigens, double-immunostaining was performed for glial fibrillary acidic protein (GFAP) plus 2 ', 3 ' cyclic nucleotide 3 ' -phosphodiesterase (CNPase), in order to differentiate between astrocytes and oligodendrocytes in the same field of view. For visualization, fluoresceinlabeled anti-mouse IgG or anti-rabbit IgG were used; all cells were additionally counterstained with Hoechst 33342. For quantification of the different fates of NSC, cells were counted manually in representative fields of view, taking into account those images displaying at least one specifically stained cell. Mean values \pm SEM were established among equally treated samples. 


\section{Real-time quantitative PCR}

All quantitative PCR experiments were performed in quadruplicate.

RNA from cells was isolated using the RNeasy Mini Kit (Qiagen, Hilden, Germany) according to the manufacturer's protocol. Total RNA concentration and purity were evaluated photometrically. Total RNA was converted to cDNA by reverse transcription with the Quantitect reverse transcription kit (Qiagen). The primer used for Ki67 was obtained from Biolegio (Nijmegen, The Netherlands). The sequences of the primers were: A) forward, TCTTGGCACTCACAGTCCAG, and B) reverse, GCTGGAAGCAAGTGAAGTCC. The quantitative PCR reaction was carried out using $10 \mathrm{ng}$ total RNA in $20 \mu \mathrm{l}$ reaction Quantitect Reagents (Qiagen) according to the manufacturer's recommendations. The samples were amplified and quantified on a Rotorgene 2000 (Corbett, Sydney, Australia) using the following thermal cycler conditions: activation, $95{ }^{\circ} \mathrm{C}, 10$ minutes; cycling, 50 cycles; step $1,92{ }^{\circ} \mathrm{C}, 15 \mathrm{~s}$; step $2,52{ }^{\circ} \mathrm{C}, 15 \mathrm{~s}$; step 3 , $72{ }^{\circ} \mathrm{C}, 40 \mathrm{~s}$. PCR product integrity was evaluated by melting point analysis and agarose gel electrophoresis. Each sample was normalized to RPL13a as reference gene, and Ki67 mRNA levels were normalized to endogenous RPL13a expression $(\triangle \mathrm{CT})$; normalized values were then expressed as $2-\Delta C t$. Mean values \pm SEM were calculated for treated and untreated cells.

\section{In vivo experiments}

All animal procedures were in accordance with the German Laws for Animal Protection and were approved by the local animal care committee (Tierschutz-Ausschuss FZ Juelich) and local governmental authorities (LANUV NRW, AZ 84-02.04.2011.A169).

\section{Photothrombosis}

Adult male Fisher 344 rats weighing 200-300 g ( $\mathrm{n}=15)$ were subjected to photothrombosis as a model of focal cerebral ischemia. Animals were anesthetized by intraperitoneal injection of ketamine $(75 \mathrm{mg} / \mathrm{kg})$ and medetomidine $(0.3 \mathrm{mg} / \mathrm{kg})$, and placed in an atraumatic stereotactical frame. The scalp was incised to expose the skull surface. For illumination, a fiber-optic bundle with a $1.5 \mathrm{~mm}$ aperture was placed onto the skull, using the stereotactic coordinates $2 \mathrm{~mm}$ posterior and $3 \mathrm{~mm}$ lateral from bregma. The skull was illuminated with a cold, white light beam $(150 \mathrm{~W})$ for 20 minutes. During the first 2 minutes of illumination, the dye rose bengal (1\%, $1 \mu \mathrm{l} / \mathrm{g}$ bodyweight) was injected into the tail vein. Afterwards, the scalp incision was sutured, and animals were given an analgesic medication and allowed to recover from anesthesia. Then they were put back into their home cages, where they were given access to food and water ad libitum.

\section{OPN treatment}

To assess the effects of OPN on endogenous NSC, in vivo animals subjected to photothrombotic stroke and naïve adult male Fisher 344 rats weighing 200-300 g were treated with a single intracerebroventricular (i.c.v.) injection of either $500 \mu \mathrm{g}$ recombinant OPN ( $R \& D$ Systems) in $5 \mu$ l saline (stroke, $\mathrm{n}=7$; naïve, $\mathrm{n}=5$ ), or $5 \mu \mathrm{l}$ saline only as control (stroke, $\mathrm{n}=8$; naïve, $\mathrm{n}=5$ ), using the stereotactic coordinates from bregma: anteroposterior $-0.9 \mathrm{~mm}$, medio-lateral $+1.4 \mathrm{~mm}$, ventrodorsal $+3.8 \mathrm{~mm}$. In stroke rats, i.c.v. injection was performed in the same session as induction of photothrombosis. After surgery, animals were given an analgesic medication, were allowed to recover from anesthesia and were put back into their home cages, where they were given access to food and water ad libitum.

To label dividing (stem) cells in vivo, the tracer bromodeoxyuridine (BrdU) was injected subcutaneously every other day for 7 days at a dose of $50 \mathrm{mg} / \mathrm{kg}$ per injection, starting on the day after i.c.v. injection of OPN or placebo, respectively, leading to a cumulative dose of $200 \mathrm{mg} / \mathrm{kg}$ BrdU per animal.

Eight days after stroke and/or i.c.v. injection, rats were sacrificed under deep anesthesia. Brains were extracted and stored at $-80{ }^{\circ} \mathrm{C}$ for further processing.

\section{Immunohistochemistry}

Coronal brain sections of $20 \mu \mathrm{m}$ were cut throughout the entire brain and fixed with $4 \%$ PFA. To quantify the number of endogenous NSC that had divided in the week following OPN treatment, sections were stained for BrdU incorporated into those cells (mouse monoclonal, clone BU-33, dilution 1:200, cat-\# B2531, SigmaAldrich). For antigen-retrieval prior to BrdU-staining, sections were microwave-heated in $0.01 \mathrm{M}$ citrate buffer, $\mathrm{pH} 6.0$, for 5 minutes, followed by $2 \mathrm{~N} \mathrm{HCl}$ at $37{ }^{\circ} \mathrm{C}$ for 30 minutes. To assess the effect of OPN on neurogenesis, sections were additionally stained for doublecortin (DCX; goat polyclonal, dilution 1:800, cat-\# sc-8066, Santa Cruz Biotechnology, Dallas, USA). To assess the effect of OPN on synaptogenesis, the sections were stained for Synapsin-1 (rabbit polyclonal; dilution 1:1000, cat-\#ab64581, Abcam). For visualization of all primary antibodies, the ABC Elite kit (Vector Laboratories, Burlingame, USA), with diaminobenzidine (Sigma-Aldrich) as the final reaction product, was used.

Representative images were taken throughout the SVZ using a digital microscope (Keyence BZ-9000E). The number of BrdU-positive cells in the SVZ was counted manually, and mean values \pm SEM were established across animals of the same treatment group. To quantify neuroblasts in the SVZ, the area covered by DCXpositive cells was measured in $\mu^{2}$ using the software BZ-II Analyzer (Keyence). 


\section{Statistical analysis}

Descriptive statistics and Student's t-tests were performed with Microsoft Excel 2003 (Microsoft Corp., Redmond, WA, USA). For comparison of multiple groups, one way analysis of variance (ANOVA) was performed, following Dunnett's method for multiple comparisons. Statistical significance was set at the less than $5 \%$ level $(p<0.05)$.

\section{Results}

\section{Undifferentiated NSC abundantly expressed CXCR4}

Primary fetal rat NSC were grown in monolayer cultures and characteristically expressed SOX2 as a marker for undifferentiated cells (Fig. 1a). Immunocytochemical staining revealed that the cytokine receptor CXCR4 was expressed on nearly all primary NSC (Fig. 1b). This abundant expression was unaffected by treatment with $6.25 \mu \mathrm{g}$ OPN for $24 \mathrm{~h}$ (Fig. 1c).

\section{OPN increased NSC numbers via CXCR4 signaling}

To investigate the effect of OPN on NSC numbers, cells were treated with OPN of various concentrations for 72 h. The number of viable NSC after this time was determined by co-staining cell nuclei with propidium iodide, thereby identifying and excluding dead cells (Fig. 2a). The number of viable NSC was significantly increased after treatment with $6.25 \mu \mathrm{g} / \mathrm{ml}$ and $12.5 \mu \mathrm{g} / \mathrm{ml} \mathrm{OPN}(p<0.05$; Fig. 2a, b). Blockage of CXCR4 with $10 \mu \mathrm{M}$ AMD $31001 \mathrm{~h}$ prior to OPN-treatment completely blocked the positive effect of OPN on NSC numbers $(p<0.05)$, while treatment with AMD 3100 alone (without OPN) had no impact on NSC numbers (Fig. 2a, b).

Since OPN at a concentration of $6.25 \mu \mathrm{g} / \mathrm{ml}$ led to the highest increase in cell number, we used this concentration for all further experiments.

\section{OPN increased both proliferation and survival of NSC}

We further analyzed whether the positive effect of OPN on NSC numbers was due to increased cell proliferation, enhanced cell survival, or both.

To study the effects of OPN on NSC proliferation, we analyzed the expression of the established proliferation marker Ki67 both on the mRNA and the protein level.
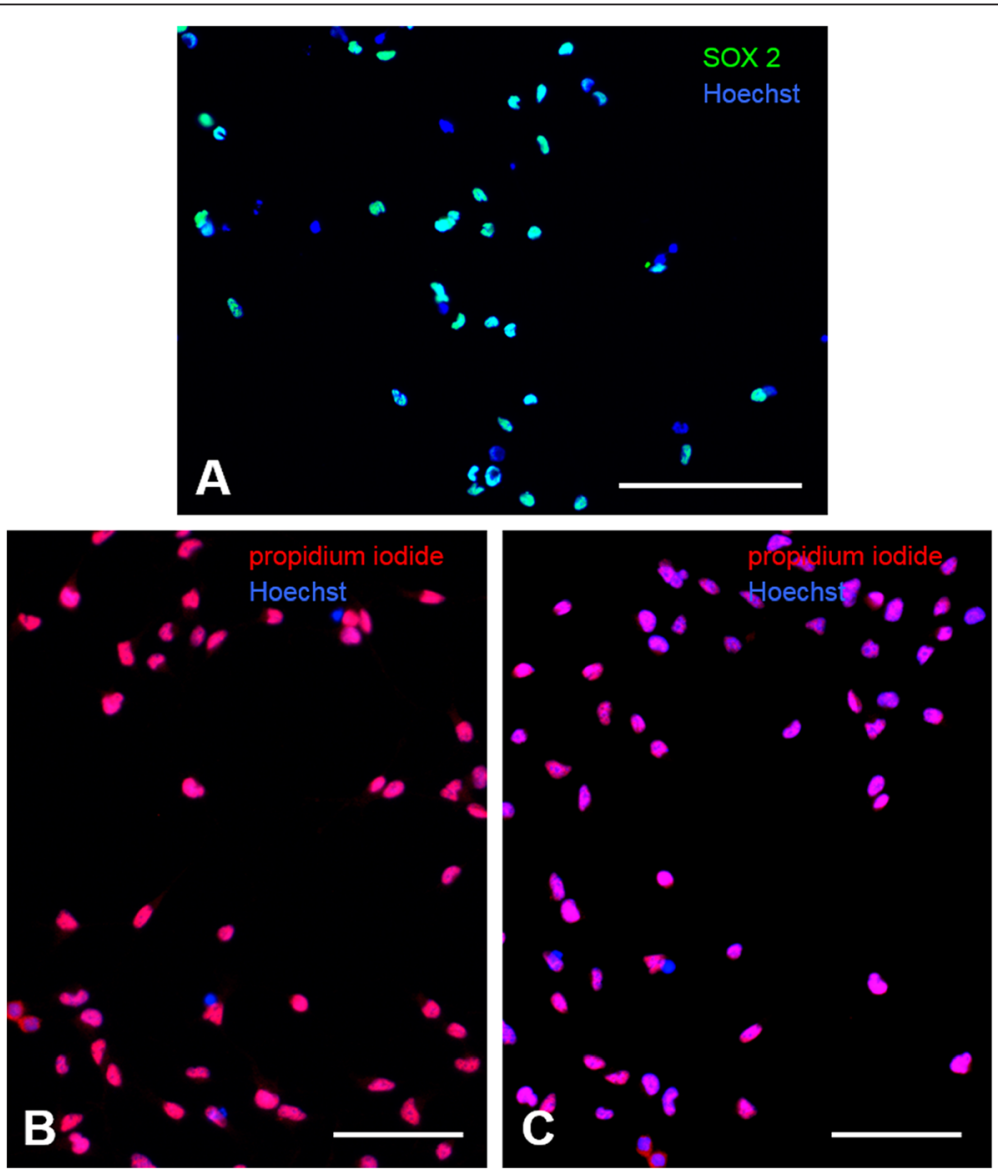

Fig. 1 Undifferentiated NSC abundantly expressed CXCR4. a Primary fetal rat NSC expressed SOX2 as a marker for undifferentiated cells (green); cells were counterstained with Hoechst (blue; scale bar represents $100 \mu \mathrm{m}$ ). b Staining for CXCR4 (red) revealed that the cytokine receptor was expressed abundantly on primary NSC; cells were counterstained with Hoechst (blue; scale bar represents $50 \mu m$ ). c Treatment with $6.25 \mu \mathrm{g}$ OPN for $24 \mathrm{~h}$ did not change the abundant expression of CXCR4 (red) on NSC (blue: counterstaining with Hoechst; scale bar represents $50 \mu \mathrm{m}$ ) 

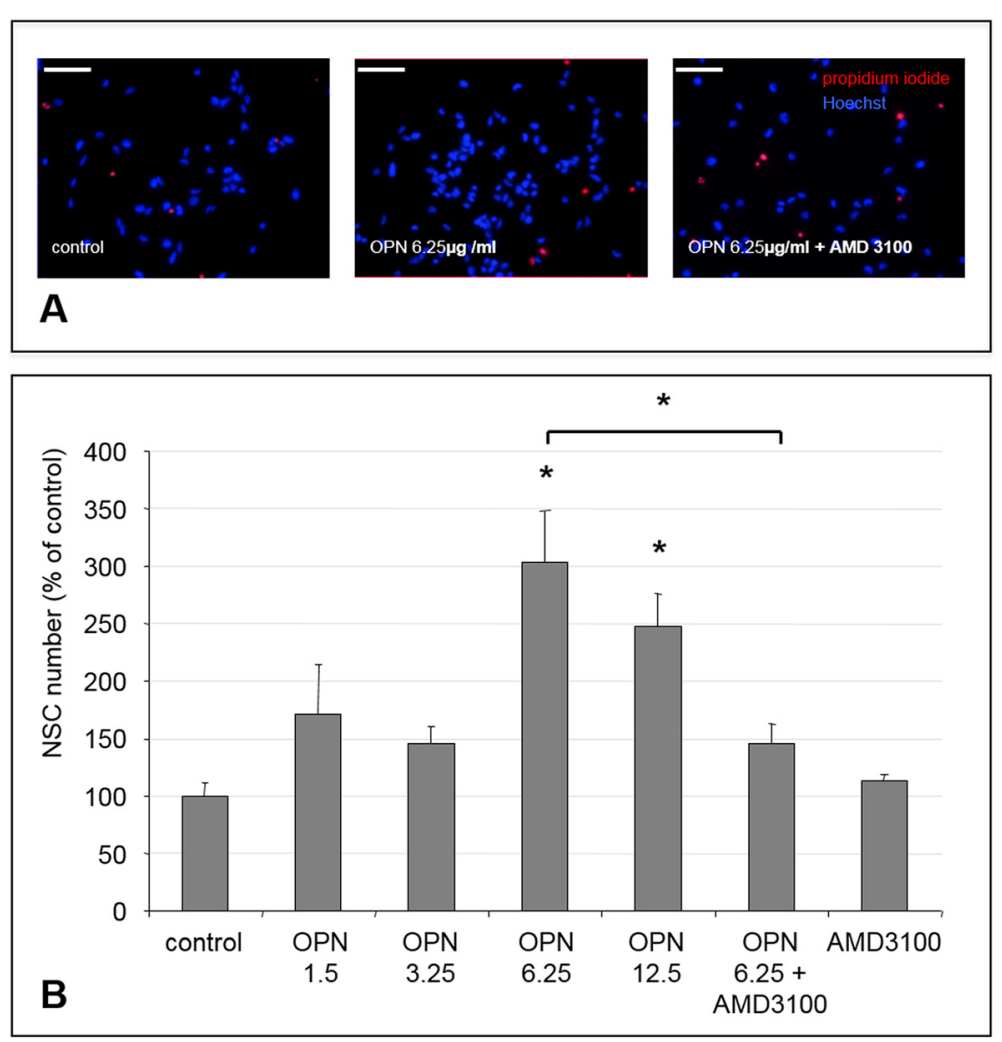

Fig. 2 Osteopontin (OPN) increased neural stem cell (NSC) numbers via CXCR4 signaling. a Left panel: Untreated NSC (control) were stained with Hoechst (blue), while dead NSC were additionally labeled with propidium iodide (red), allowing calculation of a ratio of viable NSC. Middle panel: After treatment with $6.25 \mathrm{\mu g} / \mathrm{ml}$ OPN for $72 \mathrm{~h}$, the number of viable NSC was increased. Right panel: Addition of AMD3100 to OPN-treated NSC abrogated this effect (scale bar represents $100 \mu \mathrm{m}$ ). b OPN at concentrations of 6.25 and $12.5 \mu \mathrm{g} / \mathrm{ml}$ significantly increased the numbers of NSC compared to control. Blocking CXCR4 with AMD 3100 for $1 \mathrm{~h}$ prior to OPN treatment completely abrogated the positive effect of OPN on NSC numbers, while AMD 3100 alone had no effect (values displayed as means \pm SEM; ${ }^{*} p<0.05$ )

Ki67-mRNA was quantitatively assessed after OPN treatment using real-time quantitative PCR. NSC treated with $\mathrm{OPN}$ at $6.25 \mu \mathrm{g} / \mathrm{ml}$ for $72 \mathrm{~h}$ yielded significantly more Ki67-mRNA than untreated NSC ( $p<0.01$; Fig. 3a). Immunocytochemically, the percentage of Ki67-positive cells was significantly increased after treatment with 6.25 $\mu \mathrm{g} / \mathrm{ml}$ OPN for $72 \mathrm{~h}$ as compared to untreated cells, corroborating quantitative PCR data at the protein level (Fig. 3b).

To assess whether OPN exerted a similar effect on NSC proliferation in vivo, adult male Fisher rats were injected with a single dose of $500 \mu \mathrm{g}$ OPN into the lateral ventricle of the brain, and compared to sham-injected animals. For the following 8 days, BrdU was repetitively administered systemically to label proliferating (stem) cells in vivo. Treatment with OPN led to a significant increase in BrdU-positive cells in the SVZ as the major NSC niche, indicating that the effects of OPN on NSC proliferation in vitro were reproducible in vivo $(p<0.01$, Fig. $3 c, d)$.

To assess a potential additional effect of OPN on the survival of NSC, we exposed NSC cultures to severe oxidative stress by adding $300 \mathrm{nM} \mathrm{H} \mathrm{H}_{2} \mathrm{O}_{2}$ for $24 \mathrm{~h}$. This exposure led to an approximately threefold increase in the percentage of dead NSC, as assessed by propidium iodide staining (Fig. 3e). Pre-treatment of NSC with 6.25 $\mu \mathrm{g} / \mathrm{ml}$ OPN $24 \mathrm{~h}$ prior to oxidative stress completely rescued the viability of NSC ( $p<0.05$; Fig. 3e). Even adding OPN simultaneously with $\mathrm{H}_{2} \mathrm{O}_{2}$ prevented about half of the cells from dying, confirming a positive effect of OPN on NSC survival during cell stress $(p<0.01$; Fig. 3e). To confirm the positive effect of OPN on the survival of NSC under stress conditions, we additionally plated NSC at very low density and grew them in the presence or absence of OPN for 8 days. Treatment with $6.25 \mu \mathrm{g} / \mathrm{ml}$ OPN led to a significantly higher number of viable NSC $(p<0.05$; Fig. 3f). Of note, NSC adapted a slightly branched morphology under stress conditions, which was unaffected by OPN (Fig. 3g).

\section{OPN promoted NSC migration via CXCR4 signaling}

To assess the chemoattractant effect of OPN on NSC, a modified Boyden chamber trans-well migration assay was performed. NSC were treated with OPN at 5, 10 or $20 \mu \mathrm{g} / \mathrm{ml}$ for $48 \mathrm{~h}$ and compared to untreated cells as a 

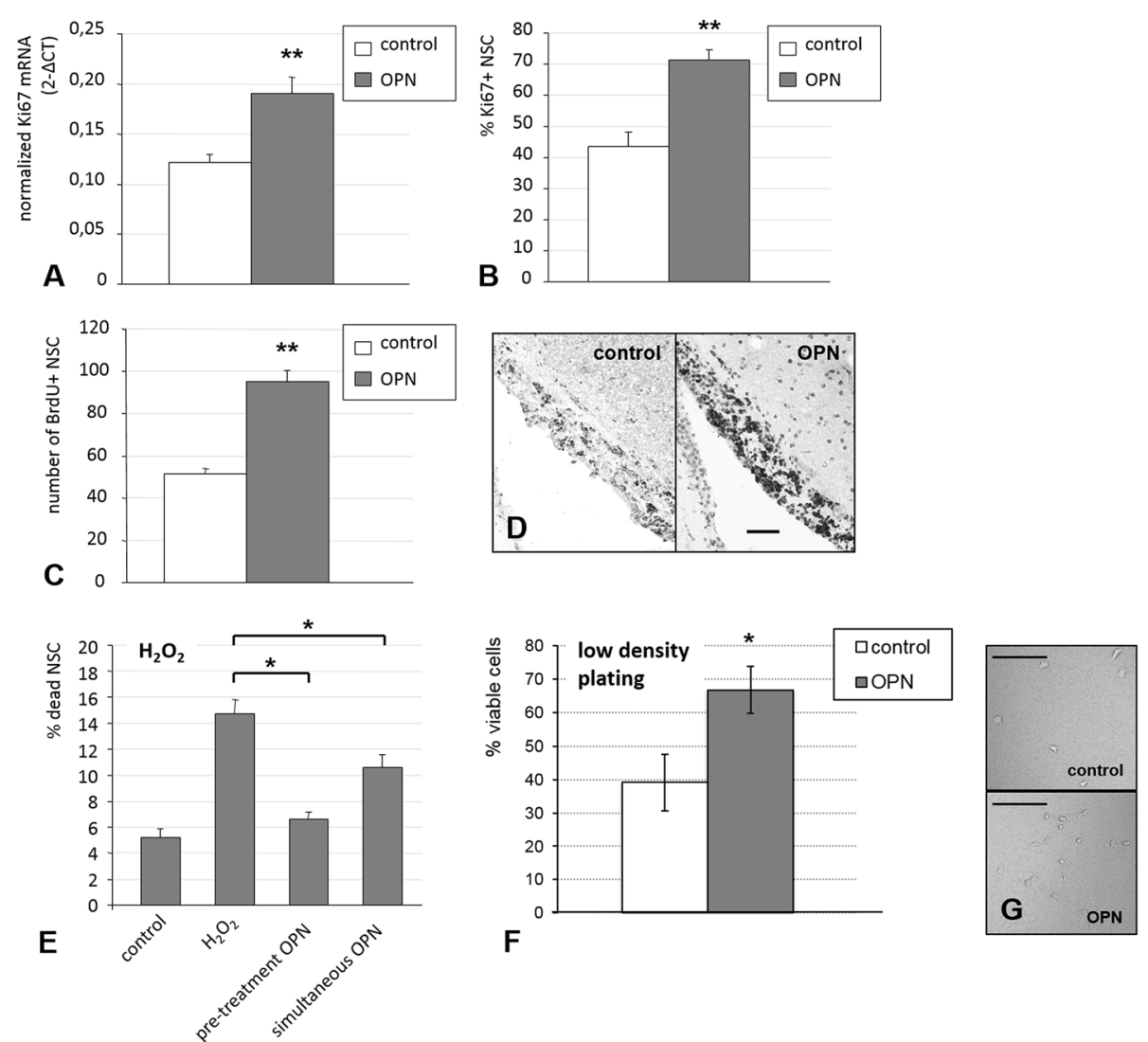

Fig. 3 Osteopontin (OPN) increased both survival and proliferation of neural stem cells (NSC). a NSC were treated with OPN at $6.25 \mu \mathrm{g} / \mathrm{ml}$ for 72 h. Quantitative PCR revealed that OPN treatment led to an increase in Ki67-mRNA, compared to untreated NSC (values displayed as means \pm SEM; $\left.{ }^{* *} p<0.01\right)$. b At the protein level, the percentage of Ki67-positive cells was significantly increased after treatment with $6.25 \mu \mathrm{g} / \mathrm{ml}$ OPN for $72 \mathrm{~h}$ (values displayed as means \pm SEM; ${ }^{* *} p<0.01$ ). c Adult male rats injected with a single dose of $500 \mu \mathrm{g}$ OPN intracerebroventricularly displayed a significantly higher number of proliferating NSC in the SVZ as the major NSC niche, corroborating the effects of OPN on NSC proliferation in vivo (values displayed as means $\pm \mathrm{SEM} ;{ }^{* *} p<0.01$ ). $\mathbf{d}$ Representative images from the SVZ of rats treated with either placebo (left) or OPN (right; scale bar represents $200 \mu \mathrm{m}$ ). e NSC cultures were exposed to oxidative stress by $\mathrm{H}_{2} \mathrm{O}_{2}$ (300 nM for 24 h), increasing cell death as assessed by propidium iodide staining. Pre-treatment of NSC with $6.25 \mathrm{\mu g} / \mathrm{ml}$ OPN $24 \mathrm{~h}$ prior to oxidative stress completely rescued NSC from this toxicity, while simultaneously addition of OPN and $\mathrm{H}_{2} \mathrm{O}_{2}$ prevented about half the cells from dying (values displayed as means \pm SEM; ${ }^{*} p<0.05$ ). $\mathbf{f}$ NSC cultures were plated at very low density $\left(266 \mathrm{cell} / \mathrm{s} / \mathrm{cm}^{2}\right)$. The numbers of living and dead cells were assessed by Hoechst and propidium iodide staining. Treatment with $6.25 \mu \mathrm{g} / \mathrm{ml}$ OPN led to a significantly higher number of viable NSC after 8 days of incubation (values displayed as means \pm SEM; ${ }^{*} p<0.05$ ). $\mathbf{g}$ NSC plated at very low density in the presence or absence of OPN at $6.25 \mu \mathrm{g} / \mathrm{ml}$ were assessed morphologically after 8 days. NSC adapted a slightly branched morphology under the stress conditions of very low density plating, independent of OPN treatment (scale bars represent $50 \mu \mathrm{m}$ ). BrdU bromodeoxyuridine

negative control; FCS as an established potent chemoattractant was used as a positive control. Upon addition of OPN at a concentration of $10 \mu \mathrm{g} / \mathrm{ml}$, a significantly higher number of NSC migrated to the lower chamber $(p<0.05$, Fig. 4). This effect was completely abolished by blocking CXCR4 with AMD $3100(p<0.05)$, while the migration-promoting effect of FCS was unaffected by AMD 3100, suggesting specific signaling of OPN via CXCR4 (Fig. 4). AMD 3100 alone had no effect on NSC migration (Fig. 4).

\section{OPN promoted neurogenesis}

To examine the effects of OPN on the differentiation potential of NSC, cells were treated with $6.25 \mu \mathrm{g} / \mathrm{ml}$
OPN, while untreated cells served as control. During the expansion phase, mitogen was withdrawn from NSC cultures to induce differentiation, and cell fate was determined immunocytochemically after 7,10 , and 14 days (Fig. 5a). Compared to untreated cells, the number of neurons doubled after OPN treatment $(p<0.01$, Fig. 5b, d). In contrast, the other cell fates (i.e., astrocytes, oligodendrocytes) as well as the remaining undifferentiated cells were slightly reduced, albeit to a non-significant extent (Fig. 5b, c).

We further focused on the effect of OPN on neurogenesis at the late time points. From day 10 of differentiation onward, an escalating formation of long neuronal processes and network-like formations was observed. 


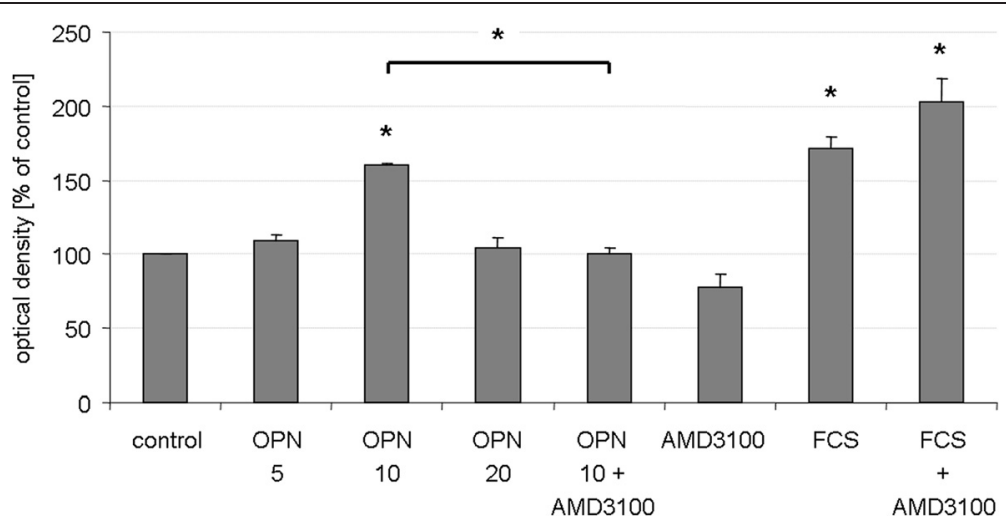

Fig. 4 Osteopontin (OPN) promoted neural stem cell (NSC) migration via CXCR4 signaling. A modified Boyden chamber trans-well migration assay was used to assess the effects of OPN on NSC migration, measuring the optical density of migrating cells, corresponding to their number. Growing NSC in the presence of $10 \mu \mathrm{g} / \mathrm{ml}$ OPN for $48 \mathrm{~h}$ significantly increased their migration, while concentrations of $5 \mathrm{and} 20 \mu \mathrm{g} / \mathrm{ml}$ did not have an effect. The positive effect of OPN on NSC migration was completely blocked by treatment with AMD 3100, indicating that the effect was mediated through CXCR4 receptor signaling. Fetal calf serum (FCS) served as positive control; its migration-promoting effect was unaffected by CXCR4 blockage. AMD 3100 alone did not affect NSC migration (values displayed as means \pm SEM; * $p<0.05$ )

Notably, this development was enhanced by OPN treatment (Fig. 5d, e). Furthermore, after 14 days of mitogen withdrawal, several NSC had differentiated into mature neurons, as indicated by immunolabeling with MAP2. OPN-treated cells generated more neurons, which, in turn, displayed denser neuronal networks (Fig. 5b, d, e).

To address the effect of OPN on neurogenesis in the rat brain in vivo, DCX-positive young neuroblasts in the SVZ were quantified 8 days after a single injection of $500 \mu \mathrm{g}$ OPN into the lateral ventricle of the brain, while placebo-injected animals served as control. While OPNtreated animals displayed a slightly larger DCX-positive area of the SVZ compared to the placebo-treated controls, this effect was not statistically significant (Fig. 6a). Under the hypothesis that OPN might promote neurogenesis to a larger extent in a model of stem cellmediated regeneration, we evaluated the effect of OPN on neurogenesis in a rat model of focal cerebral ischemia. When rats subjected to photothrombotic stroke received a single injection of $500 \mu \mathrm{g}$ OPN into the lateral ventricle of the brain, OPN-treated animals displayed significantly more DCX-positive neuroblasts in the SVZ compared to the placebo-treated controls $(p<0.01$, Fig. 6b, c).

Furthermore, we assessed the effect of OPN on synaptogenesis in the naïve rat brain in vivo. However, after 8 days, the synapsin-1-positive cells in the SVZ of OPNtreated naïve rats did not differ from control animals (Additional file 1: Figure S1).

\section{Discussion}

We found OPN to enhance both survival as well as proliferation of NSC. Data suggest that OPN increases the numbers of NSC via the chemokine receptor CXCR4. OPN has previously been shown to promote survival of various cells including bone marrow cells [42], dendritic cells [43], and cancer cells [44]. As a mechanism of action, its binding to splice variants of the cell surface glycoprotein CD44, activating the downstream PI3K pathway, has been suggested [44, 45]. Our data extend these findings by showing that beyond those types of cells, the survival of NSC exposed to oxidative stress is increased by OPN as well. This pro-survival effect of OPN on NSC under oxidative stress might facilitate survival of these cells under ischemic conditions such as stroke. Consistent with this assumption, OPN has been reported to protect neurons from ischemic injury $[18,19]$.

Previous reports have discovered diverse effects of OPN on cell proliferation. On the one hand, OPN was shown to directly increase proliferation of various tumor cells $[45,46]$. Likewise, absence of OPN has been linked to decreased cell proliferation of both tumor cells [47] and erythroblasts [48]. On the other hand, OPN has been shown to suppress proliferation of hematopoietic stem cells through the induction of quiescence [35]. Regarding NSC, thus far non-conclusive effects of OPN on proliferation have been reported: while some reports failed to detect any effect of OPN on NSC proliferation in vitro [41] or in vivo after experimental stroke [49], others showed that NSC proliferation was reduced in the absence of OPN in a mouse model of hypoxic brain injury [50], or that OPN directly induced proliferation of NSC grown as neurosphere cultures [39]. Kalluri and Dempsey suggested that these seemingly contradictory results could result from different experimental conditions: they demonstrated that OPN increased NSC proliferation in neurosphere cultures only in the presence of FGF2 [39]. In our study, we found OPN increased the proliferation in monolayer cultures of primary NSC grown in the presence of FGF2, and additionally in the 

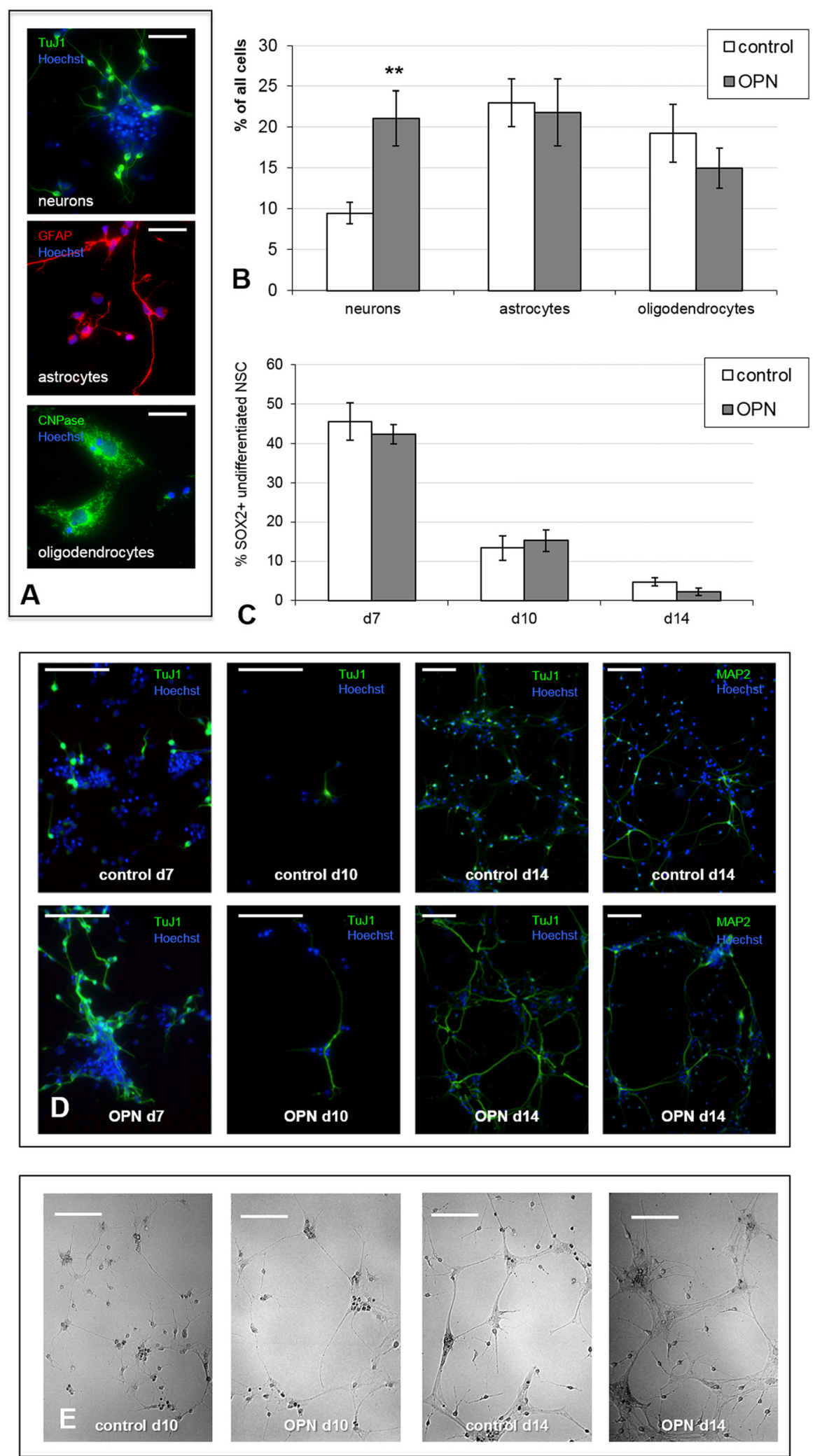

Fig. 5 (See legend on next page.) 
(See figure on previous page.)

Fig. 5 Osteopontin (OPN) promoted neurogenesis in vitro. a Neural stem cells (NSC) were allowed to differentiate for 7 days (d) after mitogen withdrawal, yielding all three cell fates: neurons (above, green), astrocytes (middle, red), and oligodendrocytes (below, green; scale bars represents $50 \mu \mathrm{m})$. b Constant exposure of NSC cultures to OPN at $6.25 \mu \mathrm{g} / \mathrm{ml}$ during differentiation led to increased neurogenesis, while other cell fates were slightly reduced, correspondently, albeit to a non-significant extent (values displayed as means \pm SEM; ${ }^{* *} p<0.01$ ). c NSC were allowed to differentiate for 7,10 , and 14 days after mitogen withdrawal in the presence or absence of OPN at $6.25 \mu \mathrm{g} / \mathrm{ml}$; the number of undifferentiated cells was subsequently assessed by staining against SRY (sex determining region Y) box 2 (SOX2). During that period, the number of undifferentiated cells continuously declined, regardless of the presence of OPN (values displayed as means \pm SEM). $\mathbf{d}$ Generation of TuJ1-positive neurons (green) during differentiation was increased by OPN treatment (lower row) as compared to control (upper row) at days 7, 10, and 14 after mitogen withdrawal. During that period, the axon length grew notably and neurons began to form networks; both observations were more pronounced in OPN-treated cells. By day 14, mature MAP2 ${ }^{+}$-positive neurons had formed (right column; scale bars represent 100 Mm). e NSC were allowed to differentiate 10 and 14 days after mitogen withdrawal in the presence or absence of OPN at $6.25 \mu \mathrm{g} / \mathrm{ml}$, and then their morphology was analyzed. Between day 10 and day 14 after mitogen withdrawal, NSC differentiation further proceeded, the neurons formed long processes and network-like formations. This effect was particularly pronounced in the OPN-treated cells (scale bars represent $100 \mu \mathrm{m}$ )
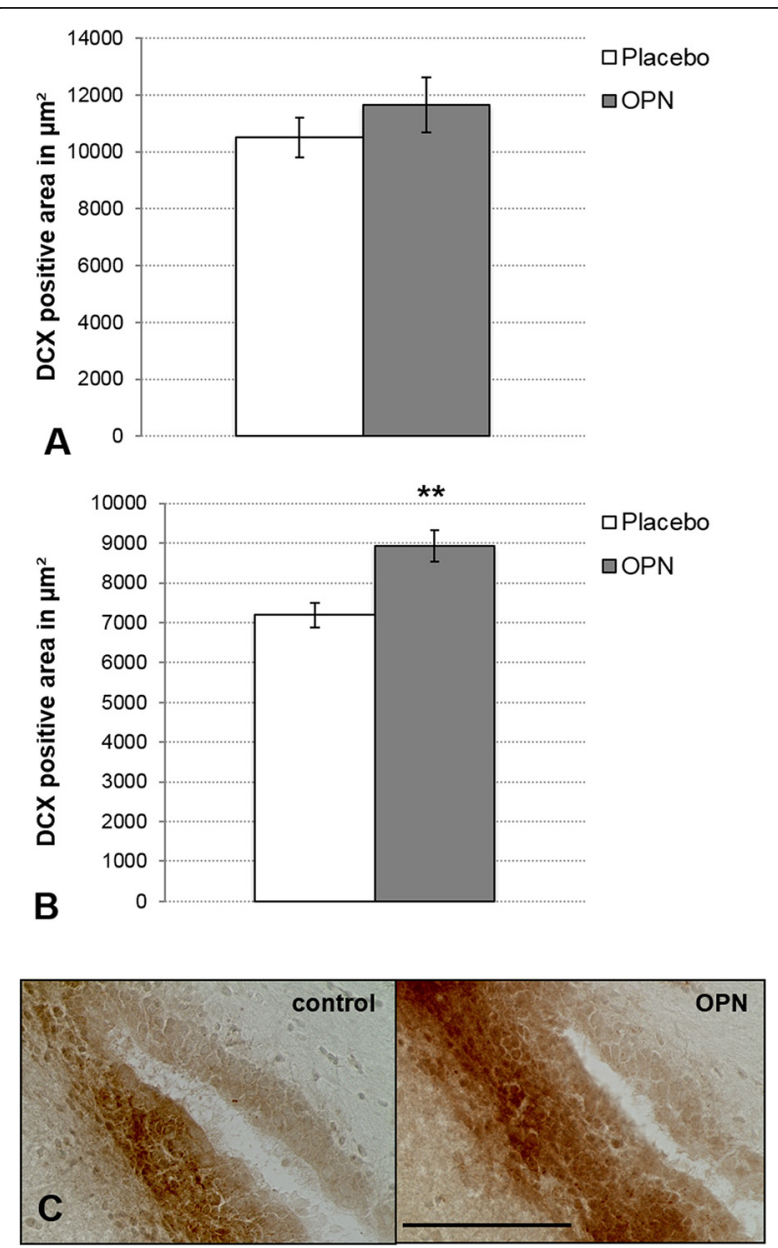

Fig. 6 Osteopontin (OPN) promoted neurogenesis after stroke in vivo. a After single i.c.v. injection of $500 \mu \mathrm{g}$ OPN in adult, unlesioned rats, OPN failed to significantly increase the area covered by doublecortin (DCX)-positive young neuroblasts in the SVZ. b In adults rats that underwent photothrombosis, a single i.c.v. injection of $500 \mu \mathrm{g}$ OPN significantly increased the area covered by DCX-positive neuroblasts in the SVZ (values are displayed as means \pm SEM, $\left.{ }^{* *} p<0.01\right)$. c Representative, DCX-stained images from the SVZ of rats subjected to cerebral ischemia, treated with either placebo (left) or OPN (right). OPN treatment led to an increase of neuroblasts in the SVZ (scale bar represents $100 \mu \mathrm{m}$ ) rat brain after stroke in vivo. Moreover, we here report for the first time that these effects are mediated via the cytokine receptor CXCR4 present on NSC.

OPN is a potent chemoattractant for various types of stem cells such as mesenchymal [34] and hematopoietic stem cells [35]. Yan et al. found that in the absence of OPN less neuroblasts migrate towards an ischemic [40] or hemorrhagic brain lesion [41]. In cultured neurospheres, they found that blocking the integrin- $\beta 1$ receptor inhibited OPN-induced migration [40], in line with a later report on OPN promoting the migration of mesenchymal stem cells via integrin- $\beta 1$ [51]. In hepatocellular carcinoma, on the other hand, OPN was shown to promote cell migration through the CXCR4 receptor [38]. We here demonstrate that migration of primary NSC grown in homogenous monolayer cultures is also mediated through CXCR4. The effects of both CXCR4 and integrin- $\alpha 4 \beta 1$ on NSC migration are consistent with their known support of the migration of hematopoietic stem cells [52]. Relevant cross-talk between these two pathways has also been described for neutrophils [53] and tumor cells $[54,55]$, and seems to also occur in the brain during autoimmune disorders [56].

To our knowledge, this is the first report describing a direct pro-neurogenic effect of OPN on NSC. Yan et al. have previously described that neutralizing OPN led to a decreased number of neuroblasts in the ischemic striatum, attributing this effect to a decreased migration of neuroblasts from the SVZ towards the striatum [40]. Plantman et al. reported a positive effect of OPN on neurite outgrowth of mature hippocampal neurons [57]. Our described direct positive effect of OPN on neurogenesis constitutes a novel aspect in stem cell-mediated regeneration after stroke, since the inflammatory milieu elicited after focal cerebral ischemia has primarily been associated with a gliogenic fate of NSC [58, 59]. Upregulation of OPN in the inflammatory environment after cerebral ischemia, as observed 3-6 days after stroke [14-17], might thus counteract the glial differentiation of NSC attracted towards the ischemic lesion, thereby 
promoting regeneration and repair. Interestingly, we observed a significant effect of OPN on neurogenesis in vivo in animals that had undergone experimental stroke. These findings further underline the concept of a regulatory role of OPN under inflammatory conditions.

\section{Conclusion}

We here demonstrate positive effects of OPN on survival, proliferation, migration and neuronal differentiation of NSC. Notably, OPN increased neurogenesis both in vitro as well as in vivo after cerebral ischemia. Since OPN is expressed in the subacute stages of focal cerebral ischemia, its impact on NSC might physiologically serve to facilitate regeneration and recovery. Our data strongly suggest that further studies investigating the in vivo use of OPN for enhancing the brain's capacity for self-repair are warranted.

\section{Additional file}

Additional file 1: Figure S1: OPN did not influence synaptogenesis in vivo. OPN failed to significantly increase the area covered by Synapsin1 -positive cells in the SVZ after single i.c.v. injection of $500 \mu \mathrm{g}$ OPN in adult rats (scale bar represents $100 \mu \mathrm{m}$ ).

\section{Abbreviations}

BrdU: bromodeoxyuridine; CNPase: 2',3'-cyclic nucleotide 3'-phosphodiesterase: CXCR4: CXC chemokine receptor type 4; DCX: doublecortin; FCS: fetal calf serum; FGF: fibroblast growth factor; GFAP: glial fibrillary acidic protein; i.c.v: intracerebroventricular; Ig: immunoglobulin; NSC: neural stem cells; OPN: osteopontin; PFA: paraformaldehyde; SDF: stromal cell-derived factor; WEM: standard error of the mean; SOX-2: SRY (sex determining region Y) box 2; SVZ: subventricular zone.

\section{Competing interests}

The authors declare that they have no competing interests.

\section{Authors' contributions}

MR carried out the majority of cell culture experiments and PCR analyses, performed the statistical analyses and drafted the manuscript. JH carried out some of the cell culture experiments and performed stereotactic injections into rats. AL performed part of the immunohistochemical stainings. AW and KL supervised all in vivo experiments and helped with the design and coordination of the study. GRF and MS participated in the design and coordination of the study and helped to draft the manuscript. MAR conceived of, designed and coordinated the study, helped with the statistical analyses, and finalized the manuscript. All authors read and approved the final manuscript.

\section{Acknowledgements}

This research work was supported by the Köln Fortune Program/Faculty of Medicine, University of Cologne, Germany (106/2012). We thank Mr Michael Schoeneck for excellent technical assistance.

\section{Author details \\ 'Department of Neurology, University Hospital of Cologne, Cologne, Germany. ${ }^{2}$ Cognitive Neuroscience, Institute of Neuroscience and Medicine (INM-3), Research Centre Juelich, Leo-Brandt-Straße, 52425 Juelich, Germany. ${ }^{3}$ Medical Imaging Physics, Institute of Neuroscience and Medicine (INM-4), Research Centre Juelich, Juelich, Germany.}

Received: 30 October 2014 Revised: 23 April 2015 Accepted: 13 May 2015 Published online: 22 May 2015

\section{References}

1. Uede T. Osteopontin, intrinsic tissue regulator of intractable inflammatory diseases. Pathol Int. 2011;61:265-80.

2. Butler WT. The nature and significance of osteopontin. Connect Tissue Res. 1989;23:123-36.

3. Denhardt DT, Guo X. Osteopontin: a protein with diverse functions. FASEB J. 1993;7:1475-82.

4. Giachelli CM, Liaw L, Murry CE, Schwartz SM, Almeida M. Osteopontin expression in cardiovascular diseases. Ann N Y Acad Sci. 1995;760:109-26.

5. Singh K, DeVouge MW, Mukherjee BB. Physiological properties and differential glycosylation of phosphorylated and nonphosphorylated forms of osteopontin secreted by normal rat kidney cells. J Biol Chem. 1990;265:18696-701.

6. Wang X, Louden C, Ohlstein EH, Stadel JM, Gu JL, Yue TL. Osteopontin expression in platelet-derived growth factor-stimulated vascular smooth muscle cells and carotid artery after balloon angioplasty. Arterioscler Thromb Vasc Biol. 1996;16:1365-72.

7. Wang KX, Denhardt DT. Osteopontin: role in immune regulation and stress responses. Cytokine Growth Factor Rev. 2008;19:333-45.

8. Denhardt DT, Noda M, O'Regan AW, Pavlin D, Berman JS. Osteopontin as a means to cope with environmental insults: regulation of inflammation, tissue remodeling, and cell survival. J Clin Invest. 2001;107:1055-61.

9. Brown A. Osteopontin: a key link between immunity, inflammation and the central nervous system. Transl Neurosci. 2012;3:288-93.

10. Hwang SM, Lopez CA, Heck DE, Gardner CR, Laskin DL, Laskin JD, et al. Osteopontin inhibits induction of nitric oxide synthase gene expression by inflammatory mediators in mouse kidney epithelial cells. J Biol Chem. 1994;269:711-5.

11. Ashkar S, Weber GF, Panoutsakopoulou V, Sanchirico ME, Jansson M, Zawaideh S, et al. Eta-1 (osteopontin): an early component of type-1 (cellmediated) immunity. Science. 2000;287:860-4.

12. Chabas D, Baranzini SE, Mitchell D, Bernard CC, Rittling SR, Denhardt DT, et al. The influence of the proinflammatory cytokine, osteopontin, on autoimmune demyelinating disease. Science. 2001;294:1731-5.

13. Guo H, Cai CQ, Schroeder RA, Kuo PC. Osteopontin is a negative feedback regulator of nitric oxide synthesis in murine macrophages. J Immunol. 2001;166:1079-86.

14. Ellison JA, Velier JJ, Spera P, Jonak ZL, Wang X, Barone FC, et al. Osteopontin and its integrin receptor alpha(v)beta3 are upregulated during formation of the glial scar after focal stroke. Stroke. 1998;29:1698-706. discussion 1707

15. Hur EM, Youssef S, Haws ME, Zhang SY, Sobel RA, Steinman L. Osteopontininduced relapse and progression of autoimmune brain disease through enhanced survival of activated T cells. Nat Immunol. 2007:8:74-83.

16. Hedtjärn M, Mallard C, Hagberg H. Inflammatory gene profiling in the developing mouse brain after hypoxia-ischemia. J Cereb Blood Flow Metab. 2004:24:1333-51.

17. Wang X, Louden C, Yue TL, Ellison JA, Barone FC, Solleveld HA, et al. Delayed expression of osteopontin after focal stroke in the rat. J Neurosci. 1998;18:2075-83.

18. Doyle KP, Yang T, Lessov NS, Ciesielski TM, Stevens SL, Simon RP, et al. Nasal administration of osteopontin peptide mimetics confers neuroprotection in stroke. J Cereb Blood Flow Metab. 2008;28:1235-48.

19. Meller R, Stevens SL, Minami M, Cameron JA, King S, Rosenzweig H, et al. Neuroprotection by osteopontin in stroke. J Cereb Blood Flow Metab. 2005;25:217-25.

20. Schroeter M, Zickler P, Denhardt DT, Hartung HP, Jander S. Increased thalamic neurodegeneration following ischaemic cortical stroke in osteopontin-deficient mice. Brain. 2006;129:1426-37.

21. Liu J, Solway K, Messing RO, Sharp FR. Increased neurogenesis in the dentate gyrus after transient global ischemia in gerbils. J Neurosci. 1998;18:7768-78

22. Rueger MA, Backes $H$, Walberer $M$, Neumaier $B$, Ullrich $R$, Simard ML, et al. Noninvasive imaging of endogenous neural stem cell mobilization in vivo using positron emission tomography. J Neurosci. 2010;30:6454-60.

23. Nakatomi H, Kuriu T, Okabe S, Yamamoto S, Hatano O, Kawahara N, et al. Regeneration of hippocampal pyramidal neurons after ischemic brain injury by recruitment of endogenous neural progenitors. Cell. 2002;110:429-41.

24. Chopp M, Li Y, Zhang ZG. Mechanisms underlying improved recovery of neurological function after stroke in the rodent after treatment with neurorestorative cell-based therapies. Stroke. 2009;40:S143-5. 
25. Arvidsson A, Collin T, Kirik D, Kokaia Z, Lindvall O. Neuronal replacement from endogenous precursors in the adult brain after stroke. Nat Med. 2002:8:963-70.

26. Huttner HB, Bergmann O, Salehpour M, Rácz A, Tatarishvili J, Lindgren E, et al. The age and genomic integrity of neurons after cortical stroke in humans. Nat Neurosci. 2014;17:801-3.

27. Androutsellis-Theotokis A, Leker RR, Soldner F, Hoeppner DJ, Ravin R, Poser SW, et al. Notch signalling regulates stem cell numbers in vitro and in vivo. Nature. 2006;442:823-6.

28. Leker RR, Soldner F, Velasco I, Gavin DK, Androutsellis-Theotokis A, McKay RD. Long-lasting regeneration after ischemia in the cerebral cortex. Stroke. 2007;38:153-61.

29. Rueger MA, Androutsellis-Theotokis A. Identifying endogenous neural stem cells in the adult brain in vitro and in vivo: novel approaches. Curr Pharm Des. 2013;19:6499-506.

30. Klein R, Blaschke S, Neumaier B, Endepols H, Graf R, Keuters M, et al. The synthetic NCAM mimetic peptide FGL mobilizes neural stem cells in vitro and in vivo. Stem Cell Rev. 2014;10:539-47.

31. Hucklenbroich J, Klein R, Neumaier B, Graf R, Fink GR, Schroeter M, et al. Aromatic-turmerone induces neural stem cell proliferation in vitro and in vivo. Stem Cell Res Ther. 2014; doi:10.1186/scrt500.

32. Giachelli CM, Lombardi D, Johnson RJ, Murry CE, Almeida M. Evidence for a role of osteopontin in macrophage infiltration in response to pathological stimuli in vivo. Am J Pathol. 1998;152:353-8.

33. Kim JM, Min SK, Kim H, Kang HK, Jung SY, Lee SH, et al. Vacuolar-type $\mathrm{H}+-$ ATPase-mediated acidosis promotes in vitro osteoclastogenesis via modulation of cell migration. Int J Mol Med. 2007;19:393-400.

34. Raheja LF, Genetos DC, Yellowley CE. Hypoxic osteocytes recruit human MSCs through an OPN/CD44-mediated pathway. Biochem Biophys Res Commun. 2008;366:1061-6.

35. Nilsson SK, Johnston HM, Whitty GA, Williams B, Webb RJ, Denhardt DT, et al. Osteopontin, a key component of the hematopoietic stem cell niche and regulator of primitive hematopoietic progenitor cells. Blood. 2005;106:1232-9.

36. Tanhehco YC, Vogl DT, Stadtmauer EA, O'Doherty U. The evolving role of plerixafor in hematopoietic progenitor cell mobilization. Transfusion. 2013;53:2314-26.

37. Imitola J, Raddassi K, Park KI, Mueller FJ, Nieto M, Teng YD, et al. Directed migration of neural stem cells to sites of CNS injury by the stromal cellderived factor 1alpha/CXC chemokine receptor 4 pathway. Proc Natl Acad Sci U S A. 2004;101:18117-22

38. Zhang R, Pan X, Huang Z, Weber GF, Zhang G. Osteopontin enhances the expression and activity of MMP-2 via the SDF-1/CXCR4 axis in hepatocellular carcinoma cell lines. PLoS One. 2011;6, e23831.

39. Kalluri HS, Dempsey RJ. Osteopontin increases the proliferation of neural progenitor cells. Int J Dev Neurosci. 2012;30:359-62.

40. Yan YP, Lang BT, Vemuganti R, Dempsey RJ. Osteopontin is a mediator of the lateral migration of neuroblasts from the subventricular zone after focal cerebral ischemia. Neurochem Int. 2009;55:826-32.

41. Yan YP, Lang BT, Vemuganti R, Dempsey RJ. Persistent migration of neuroblasts from the subventricular zone to the injured striatum mediated by osteopontin following intracerebral hemorrhage. J Neurochem. 2009;109:1624-35.

42. Lin YH, Huang CJ, Chao JR, Chen ST, Lee SF, Yen JJ, et al. Coupling of osteopontin and its cell surface receptor CD44 to the cell survival response elicited by interleukin-3 or granulocyte-macrophage colony-stimulating factor. Mol Cell Biol. 2000;20:2734-42.

43. Kawamura K, lyonaga K, Ichiyasu H, Nagano J, Suga M, Sasaki Y. Differentiation, maturation, and survival of dendritic cells by osteopontin regulation. Clin Diagn Lab Immunol. 2005;12:206-12.

44. Lee JL, Wang MJ, Sudhir PR, Chen GD, Chi CW, Chen JY. Osteopontin promotes integrin activation through outside-in and inside-out mechanisms: OPN-CD44V interaction enhances survival in gastrointestinal cancer cells. Cancer Res. 2007;67:2089-97.

45. Luo X, Ruhland MK, Pazolli E, Lind AC, Stewart SA. Osteopontin stimulates preneoplastic cellular proliferation through activation of the MAPK pathway. Mol Cancer Res. 2011;9:1018-29.

46. Pazolli E, Luo X, Brehm S, Carbery K, Chung JJ, Prior JL, et al. Senescent stromal-derived osteopontin promotes preneoplastic cell growth. Cancer Res. 2009;69:1230-9.
47. Matsuura M, Suzuki T, Suzuki M, Tanaka R, Ito E, Saito T. Statin-mediated reduction of osteopontin expression induces apoptosis and cell growth arrest in ovarian clear cell carcinoma. Oncol Rep. 2011;25:41-7.

48. Kang JA, Zhou Y, Weis TL, Liu H, Ulaszek J, Satgurunathan N, et al. Osteopontin regulates actin cytoskeleton and contributes to cell proliferation in primary erythroblasts. J Biol Chem. 2008;283:6997-7006.

49. Sailor KA, Dhodda VK, Rao VL, Dempsey RJ. Osteopontin infusion into normal adult rat brain fails to increase cell proliferation in dentate gyrus and subventricular zone. Acta Neurochir Suppl. 2003;86:181-5.

50. van Velthoven CT, Heijnen CJ, van Bel F, Kavelaars A. Osteopontin enhances endogenous repair after neonatal hypoxic-ischemic brain injury. Stroke. 2011:42:2294-301.

51. Zou C, Luo Q, Qin J, Shi Y, Yang L, Ju B, et al. Osteopontin promotes mesenchymal stem cell migration and lessens cell stiffness via integrin $\beta 1$, FAK, and ERK pathways. Cell Biochem Biophys. 2013;65:455-62.

52. Rettig MP, Ansstas G, DiPersio JF. Mobilization of hematopoietic stem and progenitor cells using inhibitors of CXCR4 and VLA-4. Leukemia. 2012;26:34-53.

53. Petty JM, Lenox CC, Weiss DJ, Poynter ME, Suratt BT. Crosstalk between CXCR4/stromal derived factor-1 and VLA-4NCAM-1 pathways regulates neutrophil retention in the bone marrow. J Immunol. 2009;182:604-12.

54. Miura K, Uniyal S, Leabu M, Oravecz T, Chakrabarti S, Morris VL, et al. Chemokine receptor CXCR4-beta1 integrin axis mediates tumorigenesis of osteosarcoma HOS cells. Biochem Cell Biol. 2005;83:36-48.

55. Cardones AR, Murakami T, Hwang ST. CXCR4 enhances adhesion of B16 tumor cells to endothelial cells in vitro and in vivo via beta(1) integrin. Cancer Res. 2003;63:6751-7.

56. Banisadr G, Schwartz SR, Podojil JR, Piccinini LA, Lanker S, Miller SD, et al. Integrin/chemokine receptor interactions in the pathogenesis of experimental autoimmune encephalomyelitis. J Neuroimmune Pharmacol. 2014;9:438-45.

57. Plantman S. Osteopontin is upregulated after mechanical brain injury and stimulates neurite growth from hippocampal neurons through $\beta 1$ integrin and CD44. Neuroreport. 2012;23:647-52.

58. Ekdahl CT, Claasen JH, Bonde S, Kokaia Z, Lindvall O. Inflammation is detrimental for neurogenesis in adult brain. Proc Natl Acad Sci U S A. 2003;100:13632-7.

59. Monje ML, Toda H, Palmer TD. Inflammatory blockade restores adult hippocampal neurogenesis. Science. 2003;302:1760-5.

\section{Submit your next manuscript to BioMed Central and take full advantage of:}

- Convenient online submission

- Thorough peer review

- No space constraints or color figure charges

- Immediate publication on acceptance

- Inclusion in PubMed, CAS, Scopus and Google Scholar

- Research which is freely available for redistribution 